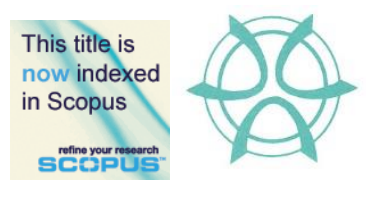

PLANNING MALAYSIA:

Journal of the Malaysian Institute of Planners

VOLUME 16 ISSUE 4 (2018), Page 117 - 129

\title{
ACCEPTANCE TOWARDS TOURISM DEVELOPMENT: THE CASE OF PERHENTIAN ISLAND
}

\author{
Diana Mohamad ${ }^{1} \&$ Badaruddin Mohamed $^{2}$ \\ ${ }^{1,2}$ School of Housing, Building and Planning \\ UNIVERSITI SAINS MALAYSIA
}

\begin{abstract}
Island tourism in Malaysia is gaining the globe's attention and has attracted people from all over the world to come to Malaysia. Islands of Malaysia have been continuously developed for the purpose of providing the visitors' with better and exclusive tourism experience. Perhentian Island is one of Malaysia's premier tourism spots famous for its crystal clear water, uncrowded beaches in addition to turtle and baby shark snorkelling points. It is learned that intense development and steady growth of tourist arrivals to this island have somehow created various positive and negative impacts. It is realized that tourism development is pressured by the need to cater to the visitors' demands while pays limited attention to the locals' needs and acceptance level. This paper reports on the tourism development impacts on Perhentian Island, looking from the point of view of locals engaged in tourism sector. Employing quantitative research approach, selfadministered questionnaire was developed with the aim of assessing the locals' acceptance level pertaining changes in social structure of Perhentian Island and negative influences of tourism development on the environment. The findings showed immediate intervention is required for re-establishment of the social structure, followed by environmental management.
\end{abstract}

Keywords: Perhentian Island, development, locals, acceptance level, social structure change, environmental impact 
Diana Mohamad \& Badaruddin Mohamed

Acceptance Towards Tourism Development: The Case of Perhentian Island

\section{INTRODUCTION}

In 2017 Malaysia has received approximately 26 million international tourists that contributed to RM82.2 billion to the country revenue (Tourism Malaysia, 2018). Given the ample benefits offered by tourism sector, notable investments were allocated which allows intense progress of tourism development especially for island tourism and Perhentian Island is no exception. Besides attractive and unique resources, successful tourism planning requires a well-established relationship between locals and tourism sector in the sense of changes in social phenomena (Liu \& Halim, 2011). Kaplan, Tekinay and Ugurlu (2013) described social phenomenon as social event that happen between individuals, and the individuals' perception towards this social event differs depending on their observations and experiences. Though complex and challenging, understanding social phenomena is fundamental in assessing acceptance level, which directly influences tourism management. As locals recognize the positive and negative consequences tourism would bring, this paper envisages understanding of the locals' acceptance level as a lens to understand their acceptance towards tourism development. Acceptance level in general is a concept used to assess ones' satisfaction in relation to frequency and/or intensity of objects/situation (Brown, Morris, \& Murry, 1996). According to Gou, Lau and Ye (2014), acceptance level is something that involves the elimination of discomfort where more specifically, it is the state of mind when an individual reacts to the changes that occur. In the context of tourism; acceptance level is an assumption of behaviour and satisfying experiences, which plays a crucial part in predicting future intention (Ramkissoon $\&$ Mavondo, 2015). This paper looks at the Perhentian Islanders' acceptance towards tourism development, assessed from the perspective of changes in social structure and environmental impacts. It seeks to address the role played by a number of parameters namely safety issues, social issues, the intensity of tourism development, migration rate, locals' participation and quality of life.

\section{LITERATURE REVIEW}

\section{Social Structure}

The social structure could interchangeably be used as a causal social structure operative and as a social organization descriptive (Little, 2007). In most cases, works of social structure linked the concept of social change with irregularities in social life which then controls the way society response with each other and to their environment (Wilterdink, 2015). The irregularities of social life could be observed along the facets of time and space where in detail, it encompasses issues related to safety, social, education and territory (Wilterdink, 2015). Rasoolimanesh, Jaafar, Marzuki and Abdullah (2017) correlated the irregularities in social life with the formation of a new political system and the entrance of new values of other cultures. Social mobility process is considered as the main cause 
PLANNING MALAYSIA

Journal of the Malaysia Institute of Planners (2018)

of irregularities of social life as this process affected the proportions of the social demographic cohorts and more importantly, the inflow social mobility process effect was deemed stronger than the outflow social mobility process. This interlinked with Rasoolimanesh et al. (2017) argument in the sense that the inclusion of non-locals (for example tourists and foreign workers) in the existing organization of society (for example Perhentian Island's community) gave impact on the economic and communication networks.

Changes in the social structure of a particular society in the forms of changes in layers of economic key players and social hierarchy could be contributed by development, which at a deeper level, influenced by types and intensity of the development undertaken (which could be used to measure acceptance towards changes in social structure). Literature on Perhentian Island presented several undesirable changes in social structure due to tourism development. For example, Bozetka (2013) put forward the ability of tourism development in influencing adaptation and/or creation of new modes of behaviour, habits and customs; and in return would contribute to the paradigm shift in social dimension (Gatewood \& Cameron, 2009). Interestingly, according to Salmond (2010), while backpackers tourism may encourage cross-cultural exchange and positively manipulate the opinion relating to the economic imbalance between locals and tourists, it also triggers the cultural sensitivity in terms of backpackers' dress code. The studies are examples of how tourism development had affected the local community of Perhentian Island (socially and culturally) and could be used as indicators in assessing the local community acceptance level towards tourism development. Though understanding the changes in social structure is challenging, it nevertheless crucial in managing the quality of life by which, influence the acceptance towards development in general and tourism development in particular.

\section{Environmental Impacts of Island Tourism Development}

Given the globe's economic growth, people are enjoying a considerable amount of dispensable income and therefore, the engagement in tourism has become impressive in size and pervasive in society. According to Stydilis, Terzidou and Terzidis (2007), the notion of enjoying island tourism was initiated by the unique characteristic of separateness offered by land and water. Positive reaction could be further enhanced provided the islands to meet the market's demand at an efficient production cost (Smith, 1994). Wong (2016) painted the island tourism as the medium to influxes of investments which accelerated the provision of infrastructure. Zaie and Zaie (2013) response to Gatewood and Cameron (2009) is in the affirmative where the provision of infrastructure benefitted both locals and tourists. As tourism is lucrative, the intense development has captured the concerns over the setbacks that tourism would bring (Nasir, Ibrahim, Mahamod, \& Othman, 2017). Seeing that the islands experience greater gravity of 
Diana Mohamad \& Badaruddin Mohamed

Acceptance Towards Tourism Development: The Case of Perhentian Island

environmental impact compared to non-island tourism destinations (Cater, 1987), it is becoming increasingly difficult to ignore the adversity effect of improper and ineffective management of environmental resource utilization (Bardolet \& Sheldon, 2008). Echoing Bardolet and Sheldon's (2008), Bozetka (2013) translated this as the continuous transformation of natural landscape into compact urbanized areas whereby, this was opposed to the central discipline of carrying capacity (Riley, 1995).

Though economic empowerment is desirable (Amir, Osman, Bachok, Ibrahim, \& Zen, 2017), serious thoughts should be directed towards the environmental impact. It is learned that the development of chalets which first taken place along the coastal localities has sprawled to the hills (Tan \& Teh, 2001), staggering number of visitors has placed pressure on sewage management and freshwater supply (Mohd Salleh, Othman, \& Harun. 2010) along with the provision of infrastructure and amenities (Ramdas \& Mohamed, 2014), and tourism activities have threatened the marine ecosystem (Comley et al., 2004); hence, signals the immediate attention for environmental conservation. This is in affirmative with Krippendorf's (1982, cited by UKEssays, 2015) who claimed that environment is the reason for engagement in and economic force of island tourism. The studies are examples of how tourism development had affected the local community of Perhentian Island (environmentally) and could be used as indicators in assessing the local community acceptance level towards tourism development. In line with the gravity of the issues at hand, scholars looked at education program to stimulate the understanding and awareness of the environment significance (Tan \& Teh, 2001) other than proposed the implementation of willingness to pay concept (Arabamiry, Abd. Rahim, Radam, Khademfar, \& Yacob, 2013), for the purpose of environmental conservation.

\section{RESEARCH BACKGROUND}

Located in the State of Terengganu, Perhentian Island (situated 25 kilometres away from Kuala Besut) consists of two main islands namely Perhentian Besar and Perhentian Kecil (Figure 1). Geologically, Perhentian Island is formed by the Eastern Belt igneous rocks (granite and syenite plutons) with a mixture of Upper Paleozoic metasedimentary (granite porphyry, microgranite and dolerite) rocks, which extends approximately 600 kilometres long (Azman, 2001). Perhentian Island, with an area of 3439 acres, can be reached by boat that takes less than 30 minutes per trip. It is well-known for its mesmerizing laid-back atmosphere, natural beauty and crystal clear water. Perhentian Island, in general, is famous for its snorkelling and scuba diving activities especially the shark, turtle and fish spots namely Tokong Laut and Sugar Wreck (NUS Dive Club, 2013). While Perhentian Kecil popularity lies with the young backpackers, Perhentian Besar is more recognized for its 13 luxury accommodations and relaxed ambiance (Hamzah \& Hampton, 2011). 


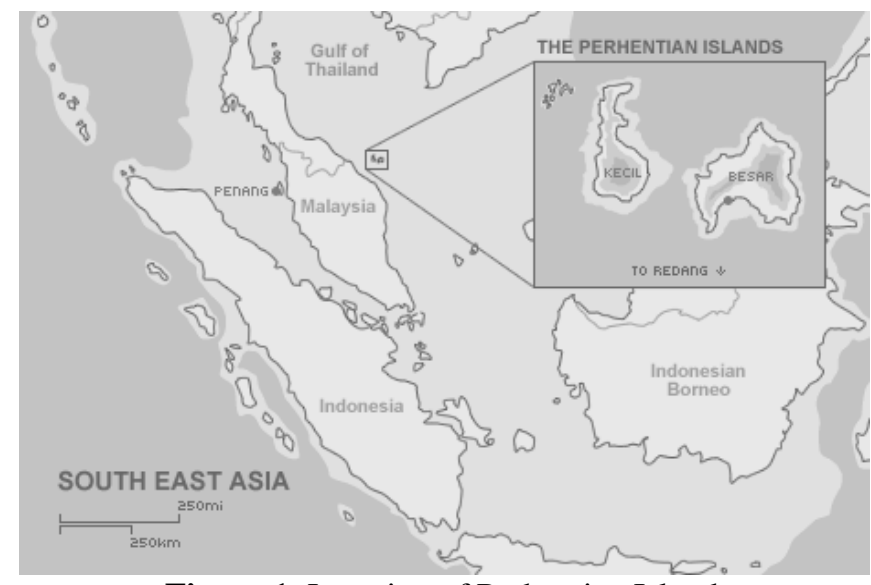

Figure 1: Location of Perhentian Island Source: UKessays (2015)

\section{RESEARCH METHOD}

This paper employed the self-administered questionnaire survey approach as the data collection instrument. The instrument covered the following aspects: (1) pollution, deforestation and land fertility; (2) biodiversity and water quality; (3) safety and social issues; (4) locals' participation, foreign workers and governance aspect (stakeholders' responsibility, destination image). This paper expands the theory of social system as a unit of analysis by incorporating the foreign workers into Perhentian Island's society. The reason behind is the foreign workers are included as a part of the locals' economic network. The respondents' declarative responses for questions asked was measured using Likert scale approach first introduced by Rensis Likert in 1932 and since, been widely used in social sciences studies (Li, 2013). Respondents were asked to answer on a 5-point Likert scale (1: strongly disagree, 3: neutral, 5: strongly agree). Based on confidence level of $90 \%$ and margin of error 5\%, the sample size needed for the survey was 271 respondents. The $90 \%$ confidence level was employed because of the heterogeneous in the social structure of Perhentian Island, while the 5\% margin of error was chosen as the respondents will be assisted by the enumerators during the survey completion. Targeting respondents with minimum age of 18 years old, 400 questionnaires were distributed to the respondents who are engaged in the tourism sector. The 5-point Likert scale (1: strongly disagree (SD), 2: disagree (D), 3: neutral (N), 4: agree (A) and 5: strongly agree (SA)) was utilized to evaluate the islanders' (minimum age of 18) perceptions and opinions regarding their acceptance level. The reliability and validity of the data collection instrument was first tested where the instrument was distributed to students and lecturers who are not majoring in planning and tourism courses. This serves the purpose of ensuring the instrument was constructed to the locals' understanding. For the purpose of analysis, 18 items were chosen and categorized into 
Diana Mohamad \& Badaruddin Mohamed

Acceptance Towards Tourism Development: The Case of Perhentian Island

environment and social structure constructs using the literature presented as reference (Table 1).

Table 1: Items assessing the acceptance level in Perhentian Island

\begin{tabular}{|c|c|c|}
\hline Items tested & Code & Construct \\
\hline $\begin{array}{l}\text { High participation of young generation in } \\
\text { tourism }\end{array}$ & Young generation & \multirow{9}{*}{$\begin{array}{c}\text { Social } \\
\text { structure }\end{array}$} \\
\hline The high number of foreign workers & Foreign workers & \\
\hline Increases in social issues & Social issues & \\
\hline Increases in safety issues & Safety issues & \\
\hline Increases in locals' immigration & Immigration & \\
\hline Increases in non-locals' migration & Migration & \\
\hline Increases in overall social status & Social status & \\
\hline $\begin{array}{l}\text { Social issues should be handled by all } \\
\text { stakeholders }\end{array}$ & Social stakeholders & \\
\hline $\begin{array}{l}\text { Safety issues should be handled by all } \\
\text { stakeholders }\end{array}$ & Safety stakeholders & \\
\hline Increases in community-based activities & Community activity & \multirow{9}{*}{ Environment } \\
\hline Tourism jeopardizes natural resources & Degradation & \\
\hline Tourism develops this destination & Island development & \\
\hline Tourism provides better water quality & Water quality & \\
\hline Tourism pollutes the environment & Pollution & \\
\hline Uncomfortable with tourism activities & Tourism activities & \\
\hline Locals welcome more tourism development & Intense development & \\
\hline Tourism development is of moderate level & $\begin{array}{c}\text { Development } \\
\text { intensity }\end{array}$ & \\
\hline Tourism conserves the environ & Conservation & \\
\hline
\end{tabular}

\section{RESULTS}

This section first addresses findings related to the changes in social structure and later presents the findings relating to the environmental impacts of tourism industry; to analyse the locals' acceptance level of tourism development in Perhentian Island. From the total 400 distributed questionnaires, 366 completed questionnaires were retrieved, amounting to $91.5 \%$ response rate. Of 366 retrieved questionnaires, 354 questionnaires were found reliable to be further analysed, contributing to $96.7 \%$ validity rate. Analysis on respondents' database provides the following details: [1] gender distribution is $56.2 \%$ male and $43.8 \%$ female, [2] dominant age is 26-50 (46.0\%), followed by $18-25(38.7 \%)$ and more than $50(15.3 \%)$, [3] marital status cohort consists of $44.9 \%$ single and $55.1 \%$ married, [4] $68.4 \%$ and $22.2 \%$ of respondents have secondary and tertiary education level, [5] 54.2\% respondents were born in Perhentian Island and [6] $76.8 \%$ respondents have more than 5 years of tenure status. Chi-square analysis resulted in insignificant relationships between all 18 items and respondents' 
profile (age, gender, education level, marital status, tenure status, origins), excluding tenure status. Hence, the following discussion is strictly related to tenure status.

\section{Findings for Social Structure}

Kaiser-Meyer-Olkin values for a tenure of less than and more than 5 years were .541 and .793 , with Bartlett's Test of Sphericity for both tenure types reached statistical significance. In case of tenure less than 5 years, it appeared that items were grouped into six components ( $73.6 \%$ of the total variance explained) where only component 1 could be regressed (Table 2). While component 1 addressed the origin cohort, the remaining components measured the following: locals' participation (component 2), management of culture-related issues (components 3 and 4), an influx of foreign workers (component 5) and safety issues (component 6). Other than indicating that the locals' acceptance level was moderately measured by high occurrences of social issues, analysis showed that the acceptance level was not influenced by the ability of tourism to improve the overall status standard and stakeholders' joint responsibility to handle safety issues. Looking at tenure more than 5 years (Table 2), items were factored into three components $(76.2 \%$ of the total variance explained) where all items were valid to be regressed excluding component 3. Component 1 was formed by 6 items that evaluated organization cohort and component 2 focused on the issues management. Results emphasized the adverse gravity of changes in social structure is increasing over time especially for migration of locals and high occurrences of social issues.

Table 2: Items assessing social structure

\begin{tabular}{|c|c|c|c|c|c|c|c|c|c|}
\hline & \multicolumn{6}{|c|}{$<5$ years $(n=271)$} & \multicolumn{3}{|c|}{$>5$ years $(n=81)$} \\
\hline & 1 & 2 & 3 & 4 & 5 & 6 & 1 & 2 & 3 \\
\hline $\begin{array}{c}\text { Young } \\
\text { generation }\end{array}$ & .062 & .961 & -.003 & .030 & -.012 & .000 & .950 & -.037 & -.199 \\
\hline Foreign workers & -.017 & -.024 & -.107 & .081 & .834 & -.011 & .950 & -.041 & -.199 \\
\hline Social issues & -.040 & -.110 & -.585 & .377 & -.399 & -.016 & .492 & -.031 & -.524 \\
\hline Safety issues & .000 & -.060 & .142 & .128 & .194 & .734 & .703 & -.311 & .102 \\
\hline Immigration & .817 & .341 & -.004 & .014 & -.012 & .003 & .949 & -.038 & -.199 \\
\hline Migration & .900 & -.169 & .001 & .000 & -.002 & -.002 & .735 & -.265 & .248 \\
\hline Social status & -.016 & -.042 & -.053 & -.893 & -.080 & -.003 & .026 & .184 & .827 \\
\hline $\begin{array}{c}\text { Social } \\
\text { stakeholders }\end{array}$ & -.023 & -.056 & .785 & .179 & -.256 & -.014 & -.076 & .852 & .115 \\
\hline $\begin{array}{c}\text { Safety } \\
\text { stakeholders }\end{array}$ & -.001 & -.060 & .151 & 129 & .210 & -.684 & -.158 & .860 & .108 \\
\hline
\end{tabular}

Overall, the results of Table 3 indicated that an item could motivate more than $49.0 \%$ changes in a particular item. For locals with tenure less than 5 years, they observed the proportion of locals and non-locals as the root cause that 
Diana Mohamad \& Badaruddin Mohamed

Acceptance Towards Tourism Development: The Case of Perhentian Island

challenging their acceptance level. In case of locals with tenure more than 5 years, the organization cohort controlled by the number of foreign workers, high occurrences of safety issues and migration of non-locals. In addition, the locals acceptance level was also contested by the joint responsibility between stakeholders to handle both safety and social issues. Table 3 in addition proposed that though in the beginning the acceptance level might be driven by items separately, the relationships between items become more intricate over time. This calls for the formation of thorough management strategies from all stakeholders.

Table 3: Regression on items assessing social structure

\begin{tabular}{|l}
\hline Tenure less than 5 years \\
- immigration is $49.2 \%$ influenced by migration, $\beta=.492, t(271)=9.280, p .000$; and \\
vice versa \\
Tenure less than 5 years \\
- young generation is $100 \%$ influenced by foreign workers, $\beta=.517, t(81)=6.011, p$ \\
$.000 ;$ and vice versa \\
- social issues is not influenced by any items \\
- safety issues is $70.9 \%$ influenced by migration, $\beta=.489, t(81)=4.932, p .000$; and \\
vice versa \\
- immigration is $100 \%$ influenced by young generation, $\beta=.610, t(81)=5.625, p$ \\
- $000 ;$ and vice versa \\
immigration is $100 \%$ influenced by foreign workers, $\beta=.393, t(81)=3.624, p .001$ \\
social stakeholders is $58.3 \%$ influenced by safety stakeholders, $\beta=.583, t(81)=$ \\
$\quad 6.432, p .000 ;$ and vice versa
\end{tabular}

\section{Findings for Environmental Impact}

Kaiser-Meyer-Olkin values for a tenure of less than and more than 5 years were .601 and .637, with Bartlett's Test of Sphericity for both tenure types reached statistical significance. In case of tenure less than 5 years, it appeared that items were grouped into six components ( $75.4 \%$ of the total variance explained) where only components 1 and 2 could be regressed (Table 4). Component 1 evaluated for improvement in the quality of life and component 2 measured the tourism development management. Further observation showed that rather than combined, items community activity and degradation were best assessing acceptance level as a standalone item. Results presented the insignificance of tourism activities as a factor in examining acceptance level. Within this paper scope, tourism activities refer to changes in natural landscape into concrete landscape. In terms of tenure more than 5 years, items were categorized into 4 components ( $74.6 \%$ of the total variance explained) with all components could be regressed (Table 4). Differing from tenure less than 5 years, results indicated the insignificance of degradation as a factor in studying acceptance level. To this paper, degradation refers to the intensity of tourism development that leads to over and improper utilization of natural resources (for example deforestation and 
PLANNING MALAYSIA

Journal of the Malaysia Institute of Planners (2018)

land infertility). Component 1 dealt with the locals' conflict of interests in relation to tourism development undertaken, component 2 related to environmental awareness and quality of life, component 3 assessed the practicality of tourism development and component 4 involved the environmental management practiced by tourism development. Results in addition suggested the suitability of pairing water quality with community activity as well as pollution with development intensity in examining acceptance level, rather than combined with intense development and conservation. When comparing results of tenures, items degradation and tourism activities were found interesting as they only applicable for either tenure. More importantly, results asserted that locals with tenure more than 5 years were more toward in agreement with tourism setback where Perhentian Island is slowly filled with concrete landscape.

Table 4: Items assessing the environmental impact

\begin{tabular}{|c|c|c|c|c|c|c|c|c|c|c|}
\hline & \multicolumn{9}{|c}{$<\mathbf{5}$ years $(\mathbf{n}=\mathbf{2 7 1})$} & \multicolumn{4}{|c|}{$>\mathbf{5}$ years $(\mathbf{n}=\mathbf{8 1})$} \\
\hline & $\mathbf{1}$ & $\mathbf{2}$ & $\mathbf{3}$ & $\mathbf{4}$ & $\mathbf{5}$ & $\mathbf{6}$ & $\mathbf{1}$ & $\mathbf{2}$ & $\mathbf{3}$ & $\mathbf{4}$ \\
\hline $\begin{array}{c}\text { Community } \\
\text { activity }\end{array}$ & -.014 & -.045 & .054 & .099 & .608 & .714 & -.222 & .825 & .274 & .159 \\
\hline Degradation & -.015 & -.040 & .413 & .173 & .490 & -.647 & -.111 & .088 & -.269 & -.504 \\
\hline $\begin{array}{c}\text { Island } \\
\text { development }\end{array}$ & .886 & .041 & .003 & .000 & -.003 & .001 & .948 & .275 & -.018 & -.156 \\
\hline Water quality & .887 & .030 & -.002 & .000 & .000 & .000 & -.205 & .807 & .304 & .253 \\
\hline Pollution & -.021 & -.092 & -.571 & .594 & -.235 & -.080 & .276 & -.182 & .315 & .626 \\
\hline Tourism activities & -.020 & -.078 & -.381 & -.781 & .051 & -.130 & .950 & .272 & -.015 & -.152 \\
\hline $\begin{array}{c}\text { Development } \\
\text { intensity }\end{array}$ & -.044 & .761 & -.008 & -.003 & -.015 & .006 & .007 & -.218 & .769 & -.324 \\
\hline Conservation & -.023 & -.087 & .604 & -.058 & -.580 & .221 & .260 & -.434 & .177 & .557 \\
\hline Tourism phase & -.048 & .762 & -.007 & .003 & -.012 & .004 & -.019 & -.187 & .734 & -.419 \\
\hline
\end{tabular}

Overall, Table 5 showed that an item could at least motivate $18 \%$ changes in a particular item where at this point, results highlighted the existence of other factors that manipulated the locals' acceptance level. It was also learned that an item was specifically affected by a particular item, hence, implied the challenges in understanding the locals' acceptance level. Comparing both tenures, this paper observed an increase in importance for community activity, island development and water quality; whilst, an urgent need for changes in natural landscape (tourism activities). Further compounding these results is the realization that the locals viewed the penetration of tourism development was at a moderate level and they observed the tourism development undertaken was in parallel with practical environmental management. 
Diana Mohamad \& Badaruddin Mohamed

Acceptance Towards Tourism Development: The Case of Perhentian Island

Table 5: Regression on items assessing environmental impact

\section{Tenure less than 5 years}

- island development is $57.6 \%$ influenced by water quality, $\beta=.576, t(271)=$ $11.573, p$.000; and vice versa

- intense development is $18.6 \%$ influenced by tourism phase, $\beta=.186, t(271)=$ $3.105, p .000$; and vice versa

Tenure less than 5 years

- island development is $100 \%$ influenced by tourism activities, $\beta=1.000, t(80)=$ 510.007, $p$.000; and vice versa

- community activity is $70.3 \%$ influenced by water quality, $B=.703, t(80)=8.836$, $p .000$; and vice versa

- intense development is $48.8 \%$ influenced by tourism phase, $\beta=.488, t(80)=5.002$ $p .000$; and vice versa

- pollution is $35.0 \%$ influenced by development intensity, $B=.350, t(80)=3.347, p$ .000 ; and vice versa

\section{DISCUSSION AND CONCLUSION}

For the purpose of analysing the gravity of tourism development on acceptance level, this paper further measured the factorization values. Echoing the fundamentals of Likert Scale (Li, 2013), this paper has arranged the following 5point scale: 1: controllable issue, 2: serious yet manageable issue, 3: serious yet not a priority issue, 4: issue requires special attention, and 5: issue requires immediate attention. When analysing 18 items ( 9 each for environmental and social structure constructs) from the perspective of tenure (less and more than 5 years), findings presented three points that should receive immediate attention. First, acceptance level relating to social structure is most challenged by the young locals' migration rate, which currently stands at $88 \%$ impact level. Despite notable tourism developments undertaken in Perhentian Island, the fact that it remains as a secluded area has insinuated the intention of vacating Perhentian Island. This situation has negatively affected the labor supply which then led to the issue of influxes of foreign workers in Perhentian Island. More importantly, the results highlighted the situation is getting serious over time and this calls for an informed and practical solution. At this point, changes in social structure could be observed in two scenarios where the first scenario related to the decline in numbers of young locals that might further threaten the Perhentian Island's population distribution and growth. The second scenario involved modification of communication network especially between locals and foreign workers. In detail, it appeared that these groups experienced interchanged in thoughts and opinions mainly regarding addressing an individual. Looking at the issue discussed, this paper envisages Investment Incentive Act of 1968 (amended in 1986) as a practical and informed approach in handling the young locals' migration issue. Other than structuring the economic development of small areas, 
this Act should be expanded to cover individuals especially those who are promoting the practices of sustainable tourism.

Second, the locals' acceptance level with reference to environmental impact was explained by the locals' enjoying an improvement in the freshwater supply quality, with approximately $85 \%$ acceptance level observed. To the locals, the enjoyment was an outcome of their joint responsibility in managing and maintaining the cleanliness of Perhentian Island; rather than recognizing it as one of the benefits brought by tourism development and acknowledging the tourism development strategies undertaken for the island. Nevertheless, results indicated the decreases in quality over time, therefore, emphasized an urgent action to be executed. Third, the locals' acceptance level could also be measured through the level of environmental pollution experienced, which stands at $61 \%$ impact level. It is interesting to find that the locals' are accepting the parallel relationship between the intensity of tourism development and the adversity of pollution level. Nevertheless, to this paper, the positive reaction towards additional tourism development might be insinuated by the benefits experienced. Further compounding this is the realization of the non-linear relationship that exists between the positive reaction and the pragmatic tourism development approach practiced. Within this paper interests, both second and third points suggest the force of education and self-awareness crucially manoeuvres one's effort in attaining a better quality of life.

\section{ACKNOWLEDGEMENT}

The authors would like to extend their appreciation to the Universiti Sains Malaysia, Ministry of Higher Education, Malaysia under Trans Disciplinary Research Grant Scheme (TRGS) 2017 (Grant Name: Models of Urban Growth Tourism and Vitalization) (203/ppbgn/67611002) for granting the research grant that made this study and paper possible.

\section{REFERENCES}

Amir, S., Osman, M. M., Bachok, S., Ibrahim, M., \& Zen, I. (2017). Community-based tourism in Melaka UNESCO World Heritage Area: A success in food and beverage sector? Planning Malaysia, 15(1), 89-108.

Arabamiry, S., Abd. Rahim, K., Radam, A., Khademfar, M., \& Yacob, M.R (2013). Marine park visitors' trade-off among marine ecological attributes in Malaysia. International Journal of Business and Social Science, 4(17), 218-228.

Azman, A. G. (2001). Petrology and geochemistry of granite and syenite from Perhentian Island, Peninsular Malaysia. Geosciences Journal, 5(2), 123-137.

Bardolet, E., \& Sheldon, P. J. (2008). Tourism in archipelagos: Hawai'i and the Balearics. Annals of Tourism Research, 35(4), 900-923.

Bozetka, B. (2013). Wolin Island, tourism and conceptions of identity. Journal of Marine and Island Cultures, 2, 1-12. 
Diana Mohamad \& Badaruddin Mohamed

Acceptance Towards Tourism Development: The Case of Perhentian Island

Brown, W. S., Morris, R. J., \& Murry, T. (1996). Comfortable effort level revisited. Journal of Voice, 10(3), 299-305.

Cater, E. A. (1987). Tourism in the least developed countries. Annals of Tourism Research, 14, 202-226.

Comley, J., Walker, R., Wilson, J., Ramsay, A., Smith, I., \& Raines, P. (2004). Malaysia coral reef conservation project: Pulau Redang. Report to the Department of Marine Parks, Malaysia. Retrieved May 12, 2014 from http://www.dmpm.nre.gov.my/

Gatewood, J. B., \& Cameron, C. M. (2009). Belonger perceptions of tourism and its impacts in the Turks and Caicos Islands. Retrieved May 12, 2014 from http://www.lehigh.edu/

Gou, Z., Lau, S. S. Y., \& Ye, H. (2014). Visual alliesthesia: The gap between comfortable and stimulating illuminance settings. Building and Environment, 82, 42-49

Hamzah, A., \& Hampton, M. P. (2011). Tourism development and change in small islands: Lessons from Perhentian Kecil, Malaysia. Skudai, Malaysia: Centre for Innovative Planning and Development, Universiti Teknologi Malaysia.

Kaplan, Y., Tekinay, D., \& Ugurlu, A. (2013). Social status of sport: Sport as a social event, phenomenon and institution. International Journal of Science Culture and Sport, 1(4), 64-69.

Li, Q. (2013). A novel Likert scale based on fuzzy sets theory. Expert Systems with Applications, 40(5), 1609-1618.

Little, D. (2007). Understanding society: What is a social structure? Retrieved August 25, 2015 from http://understandingsociety.blogspot.com/

Liu, O. P., \& Halim, S. A. (2011). Planning for heritage tourism: The Case of Langkawi Geopark. Planning Malaysia, 9,121-144.

Nasir, N. M., Ibrahim, M., Mahamod, L. H., \& Othman, R. (2017). Challenges to implement carrying capacity framework: A case study of Pulau Perhentian Marine Park institutional framework. Planning Malaysia, 15(1), 163-168.

Mohd Salleh, N. H., Othman, R., \& Harun, N. F. A. (2010). The impact of marine park gazettement to local community sustainable livelihood: A case study of Redang and Tioman Islands. Retrieved May 12, 2014 from http://mpra.ub.unimuenchen.de/

NUS Dive Club (2013). Leisure trip to Perhentian Islands. Retrieved December 23, 2014 from http://nusdiveclub.org/

Ramdas, M., \& Mohamed, B. (2014). Visitor perceptions on the impacts of tourism activities, development and infrastructure on the environment of Perhentian Islands. SHS Web of Conferences 12, 010801 (2014).

Ramkissoon, H., \& Mavondo, F. T. (2015). The satisfaction-place attachment relationship: Potential mediators and moderators. Journal of Business Research, 66(12), 2593-2602.

Rasoolimanesh, S. M., Jaafar, M., Marzuki, A., \& Abdullah, S. (2017). Tourist's perceptions of crowding at recreational sites: The case of the Perhentian Islands. An International Journal of Tourism and Hospitality Research, 28(1), 41-51

Riley, M. (1995). Tourism development under close control: The case of the Falkland Islands. Tourism Management, 16(6), 471-474. 
PLANNING MALAYSIA

Journal of the Malaysia Institute of Planners (2018)

Salmond, J. L. (2010). The social relations of tourism on the Perhentian Islands (Doctorate dissertation). University of Kentucky, USA.

Smith, S. L. J. (1994). The tourism product. Annals of Tourism Research, 21(3), 582-595.

Stylidis, D., Terzidou, M. \& Terzidis, K. (2007, September). Island tourism and its socioeconomic impacts. MIBES. September 29-30, 2007, Larissa, Greece.

Tan, W. H., \& Teh, T. S. (2001). Sustainability of island tourism resorts: A case study of the Perhentian Islands. Malaysia Journal Tropical Geography, 30(1\&2), 5168.

Tourism Malaysia (2018). Malaysia tourism statistics in brief. Retrieved October 15, 2018 from https://www.tourism.gov.my/

UKessays (2015). The environment of Perhentian Island, Malaysia. Available at http://www.ukessays.com/

Wilterdink, N. (2015). Social structure. Retrieved August 25, 2015 from http://global.britannica.com/topic/social-structure

Wong, K. W. (2016, October 13). Langkawi remains a magnet for tourists. Retrieved from https://www.edgeprop.my/

Zaie, M. E., \& Zaie, M. E. (2013). The impacts of tourism industry on host community. European Journal of Tourism Hospitality and Research, 1(2), 12-21

Received: $1^{\text {st }}$ June 2018. Accepted: $1^{\text {st }}$ December 2018 